\title{
PROCESSO DE MERCANTILIZAÇÃO DA SEMENTE: ORIGEM, CONSEQUÊNCIAS AO AGRICULTOR FAMILIAR E ALTERNATIVAS
}

\author{
Maria Cristina Vidotte Blanco Tarrega ${ }^{1}$ \\ Giovanna Silva Bianchi ${ }^{2}$
}

\section{RESUMO:}

O presente estudo visa realizar uma breve análise do processo de mercantilização da semente, que passa de recurso regenerativo, envolto de saberes tradicionais e parte de ecossistemas sustentáveis, a mercadoria central do agronegócio. Esse processo envolve os modelos tecnológicos da agricultura, o processo de globalização neoliberal, a ciência reducionista e os sistemas de legais que legitimam apenas esse tipo de conhecimento como válido. Em razão dos impactos desse processo nos agricultores familiares, erige-se a agroecologia como alternativa de superação da ideia de poder mercadológico que a semente desenvolveu, resgatando seus conceitos tradicionais de recurso renovável e de liberdade.

Palavras-chave: mercantilização da semente, agricultor familiar, conhecimentos tradicionais, agroecologia, direitos socioambientais.

\section{SEED MERCANTILIZATION PROCESS: ORIGIN, CONSEQUENCES TO THE FAMILY FARMER AND ALTERNATIVES}

\begin{abstract}
:
The present study aims to perform a brief analysis of the process of commodification of the seed, which goes from regenerative resource, surrounded by traditional knowledge and part of sustainable ecosystems, to the agrobusiness' central commodity. This process involves the technological models of agriculture, the process of neoliberal globalization, reductionist science, and legal systems that legitimize only this kind of knowledge as valid. Because of the impacts of this process on the family farmers, agroecology is erected as an alternative to overcome the idea of market power that the seed developed, rescuing its traditional concepts of renewable resource and freedom.
\end{abstract}

Key-words: Commodification of the seed, family farmer, traditional knowledge, agroecology, socio-environmental rights.

\section{INTRODUÇÃO:}

A emergência de novos meios de produção e de transporte revolucionaram as condições de produção e os intercâmbios agrícolas nos "países desenvolvidos". Os

\footnotetext{
${ }^{1}$ Pesquisadora e extensionista. Mestre em Direito Civil e Doutora em Direito Empresarial pela PUC SP, é professora titular da UFG e no Programa de Mestrado da Universidade de Ribeirão Preto.

${ }_{2}^{2}$ Mestranda em Direito Agrário pela Universidade Federal de Goiás. Pós-graduanda em Direito Civil e Processo Civil pela ATAME-GO.
} 
conhecimentos tradicionais dos agricultores passaram a ser ofuscados pela implementação maciça de pacotes tecnológicos ofertados por multinacionais controladoras do mercado mundial de sementes.

Percebe-se, pois, um distanciamento progressivo do homem para com seus meios de produção, superando a ideia de produção de valores de uso e valorizando um regime de acumulação de capital, essência do capitalismo. Esta é a premissa para que sociedades capitalistas convertam em mercadoria elementos antes indissociáveis do homem, como as sementes ou, num sentido mais amplo, a própria natureza.

Isso ocorreu em razão de condições biológicas, ecológicas, de trabalho, econômicas e sociais. As condições biológicas revelam-se por meio da seleção de plantas e de animais domésticos mais exigentes e mais produtivos, principalmente com a implementação de técnicas da engenharia genética. Outrossim, as condições ecológicas traduzem-se pela simplificação dos ecossistemas cultivados especializados, o que invariavelmente reduz a biodiversidade.

Essas duas condições são facilmente visualizadas no processo de mercantilização da semente, que passa de recurso regenerativo, integrante de ecossistemas sustentáveis, a mercadoria central do agrobusiness. Ora, com esse processo, vislumbra-se a quebra da unidade da semente, de um lado como geradora de uma colheita, de outro como reprodutora de si mesma. Portanto, liga-se dialeticamente com a transformação das relações sociais na agricultura na direção de um crescente domínio do agronegócio e da agricultura em grande escala voltada para a exportação e, num certo nível de análise, está inequivocamente a serviço dos interesses das multinacionais (SHIVA, 2001).

As condições de trabalho, por sua vez, estão aliadas a implementação de motores e de máquinas tão eficientes que prescindiram do recurso à energia animal e reduziram as necessidades de mão de obra, gerando desemprego e redução de renda para vários trabalhadores, que passaram a se tornar subalimentados, ferindo o direito constitucional à alimentação.

Outrossim, as condições econômicas e sociais, nas palavras de Marcel Mazoyer e Laurence Roudart (2010), caracterizam-se pelo aumento incessante de um número cada vez mais reduzido de estabelecimentos e a exclusão progressiva da grande maioria das outras e, igualmente com o abandono às indústrias a montante e a jusante das atividades de produção, de seus meios de trabalho e de transformação de seus produtos. 
Aumentando vertiginosamente a produtividade do trabalho, esse novo sistema agrícola e alimentar mostrou-se teoricamente capaz de alimentar abundantemente toda a população, todavia, não há uma eficiente distribuição de toda a produção gerada, o que promove um aumento crescente da fome mundial. Ainda, é perceptível a presença de excessos que precisam ser corrigidos, de forma a resguardar o direito à alimentação adequada e a um meio ambiente ecologicamente equilibrado, bem como a valorização dos conhecimentos tradicionais.

Se não houver limites, por exemplo, o uso de adubos e produtos de tratamento continuará a ser empregado até seu limite de rentabilidade, ou seja, às vezes, muito além do seu limite de nocividade. Sem proibição rigorosa, produtos perigosos mais rentáveis serão utilizados. Na falta absoluta de proibição, matérias-primas duvidosas poderão ser empregadas pelas indústrias de alimentação animal, os espaços insubstituíveis serão cultivados e as espécies raras serão destruídas.

O objetivo deste artigo é analisar o processo de mercantilização da semente, suas origens, consequências ao agricultor familiar e alternativas. Para tanto, inicialmente, o texto aborda uma breve evolução da relação ser humano e natureza, que perpassa a utilização da semente como recurso regenerativo, as revoluções agrícolas e deságua na utilização da semente como mercadoria central do agronegócio.

Num segundo momento, o texto discorre sobre os impactos desse processo de mercantilização da semente ao agricultor familiar, especialmente de "países subdesenvolvidos", num contexto de ascensão dos novos meios de produção agrícola e de transportes.

Por fim, sugere-se, como alternativa à referida mercantilização, o desenvolvimento de práticas agroecológicas, com a valorização do aspecto simbólico da semente e dos saberes tradicionais a ela ligados. Aliada à adoção da agroecologia, imperiosa a utilização do Direito como instrumento de regulação social, no intuito de proteger bens e direitos socioambientais (tais quais o meio ambiente sadio, a biodiversidade, a sociodiversidade, o patrimônio cultural e os conhecimentos tradicionais) em sociedades sustentáveis para as presentes e as futuras gerações.

A metodologia empregada é a lógico-dedutiva, guardando em si a necessária coesão e coerência com fulcro ao objetivo final: respostas e indagações reflexivas para o aprofundamento do estudo, pretendendo, assim, a contribuição não somente para a 
comunidade jurídico-acadêmica, mas também um estudo que transborde para a prática agrícola existente no país.

O estudo possui pertinência e atualidade, dizer por que merece que se debrucem os cientistas e estudiosos do Direito e de áreas afins, porquanto ainda prescinde de farta doutrina específica do tema.

\section{PROCESSO DE MERCANTILIZAÇÃO DA SEMENTE}

Em tempos pré-capitalistas, o ser humano e a natureza, em sentido amplo, eram tidos como elementos indissociáveis e pertencentes a uma mesma relação dialética, representada por uma apropriação dos recursos ambientais e naturais pelo homem, com finalidade de manutenção própria e não de criação de renda e valor (HOBSBAWM, 1981).

No referido período, as sementes utilizadas nos plantios eram consideradas unicamente como entidades biológicas que se reproduziam rotineiramente. Constituíam, portanto, recursos regenerativos e partes integrais de ecossistemas sustentáveis, gerando produtos que satisfaziam necessidades locais. Eram consideradas, ainda, parte da herança comum da humanidade e compatíveis com os valores culturais e organizações sociais locais. Foram selecionadas por um número enorme de lavradores ao longo dos séculos, com métodos informados por conhecimento local (SHIVA, 2001).

Descreve Marx (1981) que, na mencionada época, a relação do homem com a natureza objetivava a produção de valores de uso e constituía um modo de sociabilidade, que se transformará somente quando o recurso natural passa a ser utilizado como insumo para a produção de valores excedentes, surgirá, então, uma ideia de progresso a partir da crescente emancipação do homem em relação à natureza e, portanto, no seu domínio cada vez maior sobre os recursos naturais, especificamente a semente.

Essa emancipação afetará tanto as forças produtivas quanto as relações de produção, eis que torna mais sofisticadas as relações interpessoais, a partir da especialização do trabalho e da troca, fomentando a alta produção de mercadorias e a acumulação de capital, bem como rompe progressivamente a relação propriedade-trabalho, ao passo em que o homem distanciase da sua relação primeva com a natureza (GAMERO; MARTINS, 2014).

Segundo Marx (1987), o trabalho é uma condição de existência biológica e cultural do homem, que demanda a promoção de uma contínua transformação da natureza, a partir da 
experiência e de valores socialmente constituídos. Com a progressiva separação entre o trabalho livre e as condições objetivas de sua realização, há um distanciamento gradual entre o homem e a natureza, superando aquele ideário inicial de semente enquanto recurso regenerativo.

Esse processo altera as relações do indivíduo com o que era a sua comunidade, a qual, no caso extremado do capitalismo, transforma-se num mecanismo social desumanizado, hostil e estranho ao próprio indivíduo (GAMERO; MARTINS, 2014).

Nesse novo paradigma, as variedades de sementes de alto rendimento, homogêneas, estáveis e dependentes de insumos externos, introduzidas pela revolução verde nos anos 1960 e 1970, adquiriram papel central. Tais sementes passaram a ser vistas como um instrumento para a transferência de tecnologia e a ampla disseminação das variedades melhoradas e de alto rendimento tornou-se um dos principais objetivos de programas de desenvolvimento agrícola financiados por organismos internacionais (SANTILLI, 2012).

Foi em meio à pressão de organismos internacionais que surgiram as leis de sementes, destinadas a orientar o desenvolvimento de um setor "moderno" e comercial de produção de sementes.

De acordo com as leis criadas na maior parte dos países, o conceito de "sementes" ficou restrito apenas aos materiais desenvolvidos por especialistas de centros de pesquisa (públicos e privados) e empresas, ao passo que as sementes tradicionalmente melhoradas e conservadas por agricultores foram excluídas do mundo formal, sendo classificadas apenas como "grãos".

Esse novo modelo agrícola adotou um "paradigma fixista", que desconsiderava variedades agrícolas que não fossem homogêneas e estáveis. Excluídas estariam, por isso, as variedades locais. Essa concepção, ainda, negou o papel dos agricultores como inovadores e detentores de saberes e práticas fundamentais para os sistemas agrícolas e para a manutenção da agrobiodiversidade no campo (SANTILLI, 2012).

Diante desse cenário, é possível verificar a ocorrência de um processo de mercantilização da semente, que passa de recurso regenerativo, parte de ecossistemas sustentáveis, a mercadoria.

Cabe lembrar, neste ponto, que Marx (1983) caracteriza a mercadoria como um objeto externo, a qual, pelas suas propriedades, satisfaz necessidades humanas de qualquer espécie. Nas sociedades capitalistas, a mercadoria possui duas propriedades principais, já 
mencionadas: seu valor de uso (a utilidade que ela apresenta a quem a consome) e seu valor de troca (medida quantificável que possibilita seu intercâmbio).

Partindo dessa conceituação de mercadoria, extrai-se que a mercantilização fundamenta-se na quebra da unidade da semente, de um lado como geradora de uma colheita, de outro como reprodutora de si mesma. Portanto, liga-se dialeticamente com a transformação das relações sociais na agricultura na direção de um crescente domínio do agronegócio e da agricultura em grande escala voltada para a exportação e, num certo nível de análise, está inequivocamente a serviço dos interesses das multinacionais (SHIVA, 2001).

Seus defensores sustentam que a mercantilização proporciona um aumento de eficiência na agricultura, e, acima de tudo, que os métodos a ela associados permitem uma produção muito maior de cereais necessários para alimentar a crescente população do planeta.

Vandana Shiva (2001) reconhece que a utilização dos métodos da Revolução Verde fez com que aumentasse dramaticamente a produção mundial de alimentos nas quatro últimas décadas, tanto assim que agora se produz comida suficiente para alimentar toda a população mundial. Ocorre que, apesar de todo esse avanço, a fome continua a assolar vastas regiões do planeta.

A conclusão inelutável é a de que, para se resguardar o respeito ao direito social e fundamental a uma alimentação adequada, conforme os ditames dos artigos $6^{\circ}$ da Constituição da República Federativa do Brasil e $2^{\circ}$ da Lei $n^{\circ}$ 11.246/2006 (Lei de Segurança Alimentar), não é suficiente produzir quantidades exacerbadas de comida, o verdadeiro problema é como fazer para que ela seja realmente bem distribuída a todas as pessoas.

Comungando desse entendimento, Jean Ziegler (2013) denuncia os grupos econômicos do setor agrícola como os causadores dessa má distribuição de alimentos e, consequentemente, os intitula como "inimigos do direito à alimentação".

Ele afirma que as duzentas maiores empresas que controlam cerca de um quarto da produção mundial com lucros astronômicos, sendo que dominam não apenas a formação dos preços e o comércio de alimentos, mas os setores essenciais da agroindústria, quais sejam: sementes, adubos, pesticidas, estocagem, transportes, dentre outros, bem como as tomadas de decisões políticas internacionais (ZIEGLER, 2013).

Aliada a essa falta de distribuição de alimentos, a utilização da semente tão somente como mercadoria leva ao desaparecimento do imenso patrimônio genético existente nos países de Terceiro Mundo. Segundo Pat Roy Mooney (1987), as alterações de produção 
nomeio rural, associadas ao desmatamento, pastoreio excessivo e destruição de reservas naturais de vida vegetal e animal resultam em uma redução drástica da biodiversidade natural dos países e, ainda, ferem o direito da população de se ter um meio ambiente ecologicamente equilibrado.

Com efeito, esse direito ao meio ambiente ecologicamente equilibrado é um direito fundamental, assegurado pelo artigo 225 da Constituição Federal Brasileira de 1988. Ao se omitir do seu dever de proteger os direitos fundamentais, ou realizá-los de forma ineficaz, o Estado estará atuando de forma inconstitucional e estará infringindo o princípio da proibição de proteção deficiente, amplamente adotado pela doutrina e jurisprudência pátrias majoritárias atuais (FELDENS, 2005).

Dessa forma, além de maximizarem a produtividade a todo custo para exportação, as multinacionais especializadas na produção de sementes ferem os direitos socioambientais quando reduzem a biodiversidade e não promovem o devido direito à alimentação adequada, já que elas exterminam as produções familiares, destroem os conhecimentos tradicionalmente armazenados por esses agricultores familiares e não distribuem corretamente os alimentos produzidos.

O desconhecimento e o menosprezo pelo passado, a excessiva pressa e a presunção inovadoras, a demasiada produtividade puramente quantitativa, as pouquíssimas precauções humanas, ecológicas e qualitativas conduzem, inevitavelmente, em longo prazo, à enorme concentração das atividades de cultivo e de criação, à perda da biodiversidade, ao excessivo esvaziamento de várias regiões, gerando expressivo êxodo e um desemprego em massa (MAZOYER; ROUDART, 2010).

A crise que atinge hoje a maioria do campesinato dos países em desenvolvimento é a fonte essencial da pobreza crescente que envolve atualmente metade da humanidade e, segundo Marcel Mazoyer e Laurence Roudart (2010), essa pobreza é a origem da atual crise da economia mundial.

\section{SITUAÇÃO DO AGRICULTOR FAMILIAR}

Paralelamente à revolução agrícola contemporânea, que provocou a descrita mercantilização da semente, a revolução dos transportes expandiu e colocou em concorrência todas as agriculturas do mundo. 
Assim, a referida revolução agrícola e seus efeitos não pararam nas fronteiras dos "países desenvolvidos". Olhando mais além, até as localidades mais distantes dos "países em desenvolvimento", descobrimos, então, de que maneira limitada e deformada esta revolução agrícola progrediu nesses países, e a que ponto as consequências do desenvolvimento desigual, da crise e da exclusão se revelam aí imensas (MOONEY, 1987).

Com efeito, as agriculturas manuais pouco produtivas, majoritárias nos "países em desenvolvimento", viram-se confrontadas, cada uma, com os baixos preços dos produtos agrícolas de base, provenientes das agriculturas mais desenvolvidas e, com o tempo, foram submetidas a uma queda exponencial dos preços agrícolas em termos reais, que resulta dos ganhos de produtividades incessantes devidos à continuação da revolução agrícola (MAZOYER; ROUDART, 2010).

Ademais, a despeito de o agricultor de subsistência, ao longo dos séculos, ter selecionado variedades que, por sua resistência e adaptação ao meio ambiente, são preciosas fontes de germoplasma para programas de melhoramento e oferecem menores riscos ao ecossistema, estas variedades não conseguem competir com as novas variedades em produtividade. E quando é o capitalismo introduzido no meio rural, a produtividade, via modernização da agricultura, é essencial à permanência do agricultor na atividade (MOONEY, 1987).

Assim, o pequeno agricultor torna-se refém dos pacotes tecnológicos introduzidos pelas multinacionais, é progressivamente privado de atividades rentáveis e presencia uma redução expressiva na biodiversidade, em decorrência do aumento na utilização de sementes híbridas e uniformemente fenotípicas. Esse cenário resulta na criação de uma massa de agricultores subequipados e pouco produtivos, com ganhos insuficientes para investir e para progredir, geralmente localizados nos "países em desenvolvimento".

Marcel Mazoyer e Laurence Roudart (2010) apontam que a baixa dos preços agrícolas reais levou os agricultores a dedicarem mais à venda que ao autoconsumo e à preservação do ecossistema cultivado, o que resultou em um enfraquecimento da força de trabalho, em uma degradação da fertilidade e, via de consequência, em uma baixa da produção. Esta se conjuga com a queda dos preços para reduzir ainda um pouco mais o ganho, já insignificante, desses agricultores.

Rapidamente atinge-se a situação em que esses agricultores, já subalimentados, não conseguem nem mesmo renovar suas sementes e seus equipamentos. Eles atingem então um 
patamar abaixo do limite de sobrevivência e não têm saída diversa do êxodo para as favelas, caso nenhum acidente econômico, biológico, climático ou político venha brutalmente agravar a situação e condená-los à fome (MAZOYER; ROUDART, 2010).

Não havendo infraestrutura urbana nem empregos suficientes na indústria e nos serviços, o êxodo do agricultor pobre e subalimentado se transformará em desemprego ou em atividades sub-remuneradas, portanto, em pobreza urbana.

Assim sendo, as quedas dos preços agrícolas e dos ganhos dos agricultores pobres levam ao aumento do desemprego, à redução dos salários básicos em todos os ramos de atividade dos "países em desenvolvimento", pouco industrializados, além de derrubarem os preços de todos os bens e serviços oferecidos por esses países.

Vislumbra-se que na maioria dos "países em desenvolvimento", a agricultura camponesa subequipada e pouco produtiva, majoritária, frequentemente tributada ou insuficientemente protegida, não teve meios de se equipar e de progredir, sendo, pois, submetida a uma concorrência Norte-Sul e a uma concorrência Sul-Sul acima de suas forças, sofrendo assim uma queda de preços que conduziu centenas de milhões de camponeses à ruína, ao êxodo, ao desemprego e à extrema pobreza (MAZOYER; ROUDART, 2010).

Acrescentam Marcel Mazoyer e Laurence Roudart (2010) que, se uma pequena fração dos agricultores arruinados financeiramente dos "países em desenvolvimento" pôde emigrar para os países industrializados e ter acesso a empregos geralmente mal remunerados, a grande maioria não teve os meios e sequer a autorização para fazê-lo. Eles tiveram ainda menos acesso às terras agrícolas e ao crédito agrícola dos "países desenvolvidos".

Isso equivale dizer que, se no mundo de hoje a livre circulação das mercadorias e dos capitais é cada vez mais efetiva, não há livre circulação de homens, e ainda menos o livre acesso à terra e ao crédito. São portanto os capitais que se deslocam para as imensas reservas de mão de obra a baixo preço, que constituem os "países em desenvolvimento" mais receptivos (MAZOYER; ROUDART, 2010).

Marcel Mazoyer e Laurence Roudart (2010) corroboram o explicitado verberando que, caso futuramente, nos "países em desenvolvimento", os preços, as rendas agrícolas e os salários permaneçam irrisoriamente baixos como se encontram atualmente, a industrialização de vários desses países se direcionará inevitavelmente à exportação a países que ainda dispõem de poder de mercado e de compra ("países desenvolvidos", países produtores de 
petróleo e alguns novos países industrializados), sendo que isso se daria em detrimento dos países já industrializados com salários mais elevados.

Nesse cenário, a industrialização dos países à custa de baixos salários levaria aos "países desenvolvidos" uma extensão do desemprego e uma diminuição dos salários tão drástica que conduziriam a um estrangulamento progressivo da demanda solvável mundial e, portanto, "à redução das possibilidades globais de investimentos produtivos e de criação de empregos, ao recrudescimento da especulação e à recessão generalizada" (MAZOYER; ROUDART, 2010, p. 548).

Para que a industrialização dos "países em desenvolvimento" participe de um verdadeiro soerguimento da economia mundial, ela deve ser fundamentada em um crescimento significativo e duradouro do poder de compra nesses países. Assim, para constituir uma demanda mundial solvável à altura das necessidades dos homens e das possibilidades de crescimento sustentável da economia, é preciso começar a elevar, de modo eficaz, progressivo e prolongado, os preços dos produtos agrícolas básicos (MAZOYER; ROUDART, 2010).

Tal elevação dos preços agrícolas é um meio eficaz para aumentar as rendas do campesinato subequipado, favorecer a superação de suas fragilidades e, em consequência, frear o êxodo agrícola, limitar o desemprego e a pobreza urbana, aumentar o nível geral dos salários e rendas, incrementar significativamente as possibilidades de receitas fiscais e de ganhos em divisas dos "países em desenvolvimento" e, finalmente, liberar capacidades de investimento que permitam a esses países se modernizar e se industrializar.

Ocorre que essa medida econômica somente será eficaz se aliada a uma legislação que promova a proteção de bens e de direitos socioambientais, garantindo a promoção de sociedades sustentáveis para as presentes e futuras gerações, bem como contribuindo para a redução da pobreza e das desigualdades ao promover valores como equidade e justiça social e ao garantir a superação dos limites do sistema jurídico proprietário e individualista atualmente vigente na maioria dos países.

O Direito, nesse ponto, atuaria como forma de regulação social e econômica, promovendo, portanto, a superação equilibrada das fragilidades agrícolas, maciçamente orientada, ou melhor, reorientada conforme o perfil do campesinato e das regiões desfavorecidas. 


\section{AGROECOLOGIA COMO ALTERNATIVA À MERCANTILIZAÇÃO DA}

\section{SEMENTE}

Pari passu, é necessário a aplicação dos diferentes métodos agrícolas que se abrigam sob o nome de agroecologia para a preservação do conhecimento tradicional, sem desprezar as possíveis contribuições da ciência reducionista.

A agroecologia ${ }^{3}$ retoma as concepções agronômicas pré-revolução verde e se apropria dos imensos progressos da ciência e da tecnologia dos últimos cinquenta anos, que se conformam em técnicas que incorporam as questões sociais, políticas, ambientais, culturais, energéticas e éticas, tendo sempre presente a escala planetária (MACHADO; MACHADO FILHO, 2014).

Essa é a agricultura para os novos tempos, que dispõe dos conhecimentos tradicionais até os modernamente apresentados à população e está apta a colocá-los em prática. Ela resgata os saberes que a Revolução Verde destruiu, incorporando-lhes os progressos científicos e tecnológicos atuais para produzir alimentos limpos e livres de venenos (MACHADO; MACHADO FILHO, 2014). Outrossim, a agroecologia dispõe dos conhecimentos para superar a monocultura e a quebra da biodiversidade, inexoráveis ao agronegócio.

Esses métodos agrícolas característicos da agroecologia utilizam fundamentalmente as sementes crioulas, locais ou tradicionais, que são aquelas melhoradas e adaptadas por agricultores, por seus próprios métodos e sistemas de manejo, desde os primórdios da agricultura, variando de acordo com as condições ambientais, os sistemas de cultivo e as preferências culturais específicas.

A atual Lei de Sementes - Lei $n^{\circ} 10.711 / 2003$-, em seu artigo $2^{\circ}$, inciso XVI, conceitua a semente crioula como sendo "variedade desenvolvida, adaptada ou produzida por agricultores familiares, assentados da reforma agrária ou indígenas, com características fenotípicas bem determinadas e reconhecidas pelas respectivas comunidades e que, a critério do Mapa, considerados também os descritores socioculturais e ambientais, não se caracterizem como substancialmente semelhantes às cultivares comerciais".

3 O termo agroecologia foi conceitualmente desenvolvido por Howard (1934). Em 1950, foi cunhado por Lysenko e passou a ser usado em cursos de agronomia até a pulverização destes cursos pelo Acordo MECUSAID, 1964-68, em plena ditadura militar. A partir de 1980, as lutas por uma agricultura limpa, que vinham desde o início da década de 1960, encontraram eco na palavra agroecologia, significando uma agricultura que incorpora as dimensões sociais, cultuais, éticas e ambientais, como fazia a agronomia pré-acordo MEC-USAID. 
Salienta-se que a adaptação dessas sementes aos ambientes locais torna desnecessário o uso de insumos químicos. Além disso, são adaptadas a sistemas de policultivo e de livre acesso e multiplicação pelos agricultores, que não precisam adquiri-las no mercado a cada safra. A disponibilidade e continuidade dessas sementes para o desenvolvimento de práticas agroecológicas tornou-se uma missão para a agricultura familiar e camponesa, fundamental para a independência e segurança alimentar dos povos.

Importante destacar, nesse ponto, que a agroecologia associa à semente a ideia de recurso renovável ou regenerativo, algo que o processo de mercantilização minou através de insumos químicos, entre outros. É também nesse sentido que a semente é para Vandana Shiva (2001): um símbolo das lutas contemporâneas.

As sementes, segundo ela, possuem diferentes facetas, sendo simultaneamente entidade biológica, parte de sistemas ecológicos e produto de desenvolvimento humano e, neste último sentido, compatíveis com valores culturais e organizações sociais locais. A mercantilização da semente quebra a articulação entre esses itens (SHIVA, 2001).

As práticas que envolvem a semente como recurso regenerativo, seus desenvolvimentos e usos, e a maneira como os agricultores se relacionam com ela, são informadas por um tipo de conhecimento diferente daquele associado à semente como mercadoria, e mais amplamente, aos modelos tecnológicos na agricultura. Quer se trate da Revolução Verde, quer da agrobiotecnologia, este conhecimento exemplifica, segundo Shiva (2001), apenas um tipo de conhecimento científico, denominado por ela ciência reducionista.

Para a referida autora, a aplicação da ciência reducionista dá origem a uma "quádrupla violência". A primeira violência, segundo ela, é efetivada contra os supostos beneficiários do conhecimento (lavradores pobres e suas famílias). As condições em que eles podem manter suas formas de agricultura são destruídas de tal maneira que eles deixam de ser produtores dos próprios alimentos, tornando-se consumidores que precisam adquiri-los, frequentemente sem dispor dos meios para isto, em virtude do deslocamento social explicado em linhas volvidas (SHIVA, 2001).

A segunda forma de violência ocorre contra os portadores de formas nãoreducionistas de ciência. A concessão de monopólio ao conhecimento obtido pela ciência reducionista, e de proteção especial por meio dos direitos de propriedade intelectual aos produtos por ela informados, desvaloriza o conhecimento dos portadores de outras formas tradicionais e agroecológicas de conhecimento, bem como as atividades por elas informadas. A 
ciência reducionista também não coloca barreira alguma aos projetos sociais e econômicos que exploram livremente tais formas de conhecimento (biopirataria), ou que diminuem sua relevância prática, e assim, a autonomia de seus portadores (SHIVA, 2001).

A terceira violência é caracterizada como a "pilhagem do conhecimento" ou violência contra o próprio conhecimento. Esta forma liga-se diretamente à segunda, e consiste na afirmação de que o conhecimento não-reducionista simplesmente não é conhecimento. Em nome do "conhecimento científico" bem estabelecido, o conhecimento tradicional (os saberes populares) é não apenas desvalorizado, mas também explorado, suprimido, distorcido e considerado não merecedor de investigação empírica e aperfeiçoamento (SHIVA, 2001).

Por fim, a última forma de violência é denominada "pilhagem da natureza" ou violência contra o objeto do conhecimento, que aborda que os projetos informados pela ciência reducionista tendem a "destruir a integridade inata da natureza e assim a despojam de sua capacidade regenerativa", e a destruir a biodiversidade e a herança genética das regiões onde são aplicados (SHIVA, 2001, p. 17).

É por tudo isso que a semente é símbolo. Como mercadoria central do agrobusiness ela simboliza pode der mercado; como recurso renovável tão caro à agroecologia representa possibilidade de fortalecimento local, autogestão, alimentação para todos, preservação da diversidade cultural e biológica, promoção da sustentabilidade ecológica e coloca alternativas à uniformidade das instituições neoliberais.

Nas palavras de Vandana Shiva (2001, p. 52):

A semente tornou-se o lugar e o símbolo da liberdade nessa época de manipulação e monopólio de sua diversidade. Ela faz o papel da roda de fiar de Gandhi no período da recolonização pelo livre comércio. A roda de fiar tornou-se um importante símbolo de liberdade não por ser grande e poderosa, mas por ser pequena; ela podia adquirir vida como sinal de resistência e criatividade nas menores cabanas e nas mais humildes famílias. Seu poder reside na sua pequenez. A semente também é pequena. Ela incorpora a biológica. Questões ecológicas combinam-se com a justiça social, a paz e a democracia.

Assim sendo, diante dessa alta carga simbólica que as sementes possuem, imperiosa é a criação de uma legislação eficaz para se garantir espaço a sua valorização, com incentivos à agroecologia e aos conhecimentos tradicionais, tendo em vista que as leis pertinentes às sementes que atualmente vigoram (e até mesmo as que vigeram no Brasil anteriormente) têm contribuído para agravar a perda da diversidade genética e sociocultural no campo, abrem 
pouco espaço de atuação aos sistemas locais e tradicionais, bem como dificultam a adoção de um modelo de agricultura sustentável, tal qual a agroecologia.

Juliana Santilli (2012) aponta que as exceções feitas às sementes locais e tradicionais pela Lei de Sementes brasileira - apesar de representarem uma conquista importante da agricultura tradicional e familiar - buscam atenuar os efeitos negativos dessa lei sobre a agrobiodiversidade, mas não alteram os princípios e conceitos gerais em que ela se baseia: setorização industrial, padronização da agricultura e a negação do papel dos agricultores como selecionadores e inovadores.

Nesse ponto, importante salientar que a referida autora testilha que o conceito do bem socioambiental denominado agrobiodiversidade ainda está em construção, porém sua ideia central reflete as dinâmicas e complexas relações entre as sociedades humanas, as plantas cultivadas e os ambientes em que convivem, tendo repercussão sobre as políticas públicas e privadas de conservação dos ecossistemas cultivados, de promoção da segurança alimentar e nutricional das populações humanas, de desenvolvimento rural sustentável e de inclusão e justiça sociais (SANTILLI, 2012).

Ventila, ainda, que tal bem consubstancia-se em um componente essencial dos sistemas agrícolas sustentáveis, apresentando características distintas em cada agroecossistema presente, exigindo soluções específicas e adequadas às suas condições socioambientais (SANTILLI, 2012).

Por tudo isso, conclui-se que as sementes representam escolhas que não são apenas agronômicas, mas também socioculturais, ambientais e econômicas, por isso a necessidade de estudá-las e valorizá-las. Para que os agricultores familiares e tradicionais possam escolher livremente as suas sementes, as políticas públicas devem promover uma ampla diversificação das sementes e conferir maior espaço legal e institucional para os sistemas locais e tradicionais, em vez de tentar impor, artificialmente, um único sistema, individualista, formal e reducionista.

\section{CONSIDERAÇÕES FINAIS}

Este trabalho constitui-se num breve ensaio sobre a problemática da mercantilização dos recursos naturais, especialmente, da semente. Esse processo de transformação da semente crioula e eivada de liberdade em mero instrumento de poder de mercado causa diversos 
problemas ambientais e sociais, pois reduz a biodiversidade, aumenta a fome mundial, gera desemprego e desigualdades.

É necessário que cada país crie uma política própria de desenvolvimento agrícola equilibrado, maciçamente orientada, ou melhor, reorientada conforme o perfil do campesinato e das regiões desfavorecidas, valorizando a agroecologia como uma forma de método agrícola que promove a preservação do conhecimento tradicional, da biodiversidade, dentre outros bens ambientais, sem desprezar as possíveis contribuições da ciência reducionista.

Aliada a essa política, imprescindível a alteração da legislação pátria, no sentido de resguardar um modelo de agricultura sustentável, que garanta a valorização dos saberes tradicionais e da simbologia primitiva da semente, visando não apenas promover a sustentabilidade ambiental, mas também a sustentabilidade social, contribuindo para a redução da pobreza e das desigualdades ao promover valores como equidade e justiça social, bem como a superação dos limites do sistema jurídico proprietário e individualista. Somente assim será possível efetivar um reerguimento exitoso da economia mundial.

Necessária, outrossim, é a melhor distribuição de alimentos entre a população mundial, para resguardar o atendimento ao direito à alimentação, tão caro e importante a diversos países, tal qual é no Brasil, tendo em vista que foi erigido à condição de direito social constitucional dos cidadãos.

Ainda, seguindo a linha de entendimento de Marcel Mazoyer e Laurence Roudart (2010), será preciso que o mundo adote novos sistemas monetários e financeiros internacionais, que garantam a manutenção de taxas de câmbio relativamente estáveis, variando nos limites razoáveis em torno das taxas de câmbio de equilíbrio fundamentais, penalizando a especulação e favorecendo, em todos os países, as políticas de desenvolvimento negociadas. Essas políticas devem buscar o pleno emprego e o aumento da demanda solvável proporcional à produção e às capacidades de investimento existentes no mundo, em vez de políticas deflacionistas redutoras de emprego e de renda.

\section{REFERÊNCIAS BIBLIOGRÁFICAS}

BRASIL. Constituição (1988). Constituição da República Federativa do Brasil. Brasília, DF: Senado Federal: Centro Gráfico, 1988. 292 p.

FELDENS, Luciano. A constituição penal: a dupla face da proporcionalidade no controle das 
normas penais. Porto Alegre: Livraria do Advogado, 2005.

GAMEIRO, Mariana Bombo Perozzi; MARTINS, Rodrigo Constante. Da mercantilização da natureza à criação de mercadorias verdes. REDD - Revista Espaço de Diálogo e Desconexão, v. 8, n. 2, p. 1-18, 2014.

HOBSBAWN, E. Introdução. In: MARX, K. Formações econômicas pré-capitalistas. Tradução de João Maia. 3.ed. Rio de Janeiro: Paz e Terra, 1981.

LACEY, Hugh. As sementes e o conhecimento que elas incorporam. São Paulo: São Paulo em Perspectiva, v. 14, n. 3, 2000.

MACHADO, Luiz Carlos Pinheiro; MACHADO FILHO, Luiz Carlos Pinheiro. A Dialética da Agroecologia: contribuição para um mundo com alimentos sem veneno. 1. ed. São Paulo: Expressão Popular, 2014.

MARX, K. Para a crítica da economia política. São Paulo: Nova Cultural - Coleção Os Pensadores, 1987. . O capital. São Paulo: Abril Cultural - Coleção Os Economistas, v.1, 1983. Formações econômicas pré-capitalistas. Tradução de Joao Maia. 3.ed. Rio de Janeiro: Paz e Terra, 1981.

MAZOYER, Marcel; ROUDART, Laurence. História das agriculturas no mundo: do neolítico à crise contemporânea. São Paulo: Editora UNESP, 2010.

MOONEY, Pat Roy. O escândalo das sementes: o domínio na produção de alimentos. São Paulo: Nobel, 1987.

NOGUEIRA, A. C. L.; ZYLBERSZTAJN, D.; GORGA, E. A ameaça da pirataria. Agroanalysis. Rio de Janeiro, v. 25, n. 8, p. 30-31, ago. 2005.

PELAEZ, V.; SCHMIDT, W. A difusão dos OGM no Brasil: imposição e resistências. Estudos Sociedade e Agricultura, Rio de Janeiro, v. 14, p. 5-31, abr. 2000. SANTILLI, Juliana. A Lei de Sementes brasileira e os seus impactos sobre a agrobiodiversidade e os sistemas agrícolas locais e tradicionais. Bol. Mus. Para. Emílio Goeldi. Ciênc. hum. [online]. 2012, vol.7, n.2, pp.457-475. ISSN 1981-8122. Disponível em: <http://dx.doi.org/10.1590/S1981-81222012000200009>, Acesso em 03 maio. 2017. SHIVA, Vandana. Biopirataria: a pilhagem da natureza e do conhecimento. Petrópolis: Vozes, 2001.

VIDAL, Ana Paula Cenci. Legislação brasileira de sementes: aplicação e eficácia na garantia da qualidade de sementes de soja. Dissertação. Mestrado Acadêmico em 
Agronegócios. UnB, 2012.

ZIEGLER, Jean. Destruição em massa. Geopolítica da fome. Tradução e prefácio de José Paulo Netto. $1^{\circ}$ ed. São Paulo: Cortez, 2013. 